\title{
Biodegradation of butyronitrile and demonstration of its mineralization by Rhodococcus sp. MTB5
}

\author{
Ismailsab Mukram ${ }^{1}$ Masarbo Ramesh ${ }^{1}$ T. R. Monisha ${ }^{1}$ - Anand S. Nayak ${ }^{1}$. \\ T. B. Karegoudar ${ }^{1}$
}

Received: 6 February 2016/ Accepted: 10 June 2016/Published online: 22 June 2016

(c) The Author(s) 2016. This article is published with open access at Springerlink.com

\begin{abstract}
A nitrile utilizing bacterium Rhodococcus sp. MTB5 was previously isolated in our laboratory by the enrichment culture technique. It is able to utilize butyronitrile as sole carbon, nitrogen, and energy source. Maximum butyronitrile degrading property of this strain has been investigated. Results reveal that 100, 98, and $88 \%$ degradation was achieved for $2,2.5$, and $3 \%$ butyronitrile, respectively. The strain is capable of growing in as high as $5 \%$ butyronitrile concentration. A two-step pathway involving nitrile hydratase (NHase) and amidase was observed for the biodegradation of butyronitrile. Complete degradation (mineralization) of butyronitrile with the help of metabolite feeding experiment was reported. The significance of this investigation was the capability of the strain to completely degrade and its ability to grow on higher concentrations of butyronitrile. These potential features make it a suitable candidate for practical field application for effective in situ bioremediation of butyronitrile contaminated sites.
\end{abstract}

Keywords Butyronitrile - Rhodococcus sp. MTB5 ·

Complete degradation - Metabolite feeding

\section{Introduction}

Nitriles are the cyanide containing compounds ( $-\mathrm{CN})$ and are widespread in the environment as a result of biological and industrial activity (Legras et al. 1990). They are used

T. B. Karegoudar goudartbk@gmail.com

1 Department of Biochemistry, Gulbarga University, Kalaburagi 585106, Karnataka, India as preliminary materials for the synthesis of a numerous fine chemicals (Banerjee et al. 2002). Butyronitrile is an aliphatic nitrile, clear colourless liquid with a suffocating odour resembling bitter almond oil. It is miscible with most polar organic solvents, hence finds applications in the industries in making other chemicals. It is mainly used as a precursor to the poultry drug amprolium (Peter et al. 2002). Amprolium is a coccidiostat (antiprotozoal agent) used in the poultry that acts upon coccidia parasites. Amprolium is prepared using commercially available butyronitrile as starting material. It is also used in electrolyte composition in dye-sensitized solar cells (Sauvage et al. 2011). A number of nitriles have been reported as potent carcinogenic, mutagenic, and toxic in nature (Ramakrishna et al. 1999). The use of nitriles as bulk solvents has increased their distribution in the environment and needs their remediation (Ebbs 2004). The chemical hydrolysis of these compounds necessitates harsh conditions, such as extremes of $\mathrm{pH}$ and elevated temperatures with the creation of significant quantities of by-products and secondary pollutants (Kobayashi and Shimizu 2000; Prasad et al. 2009). Bioremediation is one such method used for the detoxification of contaminated sites. It is an inexpensive technology, and can either eliminate these compounds by degrading them to harmless intermediates or, in due course, to carbon dioxide and water (Nawaz et al. 1991).

The nitrile converting enzymes occur in a wide variety of plants, bacteria, and in some fungi. The microbial hydrolysis of nitriles begins through two key enzymatic pathways (Fig. 1). First, the nitrile hydratases hydrolyze nitriles to amides and by amidases to the corresponding carboxylic acids and ammonia (Kobayashi and Shimizu 1998; Sharma et al. 2013). Second, nitrilases directly convert nitriles to acids and ammonia (Kobayashi and Shimizu 2000). 

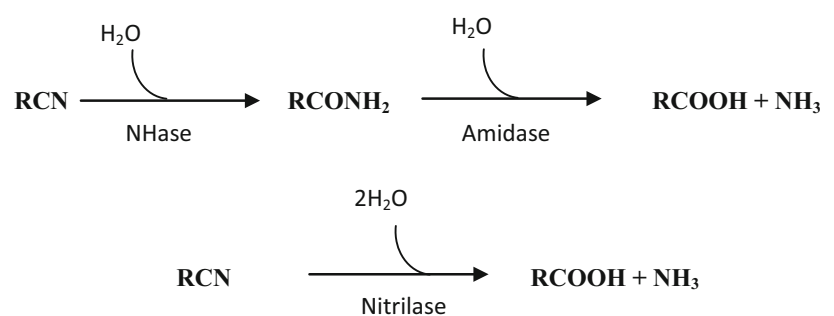

Fig. 1 General catabolic pathways (NHase: amidase and nitrilase) for degradation of organic nitriles

Microbial degradation of different types of nitriles has been reported using different strains (Wang et al. 2007; Chen et al. 2010; Fang et al. 2015). However, there are limited reports in the literature about the biodegradation of butyronitrile (Wenzhong et al. 1991; Nawaz et al. 1992). To the best of our knowledge, no reports are available on the proof of complete degradation of nitriles by metabolite feeding experiment. In the present communication, we report the maximum degradation of butyronitrile of $3 \%$ and the ability of the strain to grow in a mineral salts (MS) medium containing as high as $5 \%$ butyronitrile. This is the first report on the highest degradation of any nitrile reported and the confirmation of complete degradation by metabolite feeding experiment.

\section{Materials and methods}

\section{Bacterium, media, and growth conditions}

Rhodococcus sp. MTB5 used in the present study was previously isolated in our laboratory (Mukram et al. 2015). For butyronitrile degradation studies, the bacterium was grown in MS medium supplemented with butyronitrile as carbon and nitrogen source. Medium composition was the same as explained previously (Mukram et al. 2015). The $\mathrm{pH}$ of the medium was adjusted to 7.0 using $2 \mathrm{~N} \mathrm{NaOH}$ or $2 \mathrm{~N} \mathrm{HCl}$. Cells were grown in $250 \mathrm{ml}$ Erlenmeyer flasks with shaking at $180 \mathrm{rpm}$ in orbital shaker at $30{ }^{\circ} \mathrm{C}$.

\section{Butyronitrile degradation}

The degradation of butyronitrile was carried out for freely suspended cells of Rhodococcus sp. MTB5. A series of batch experiments were carried out in $250 \mathrm{ml}$ flasks containing $50 \mathrm{ml}$ of autoclaved medium loaded with different concentrations of filter sterilized butyronitrile $(2,2.5$, and $3.0 \% \mathrm{v} / \mathrm{v}$ ) and with suitable controls. The butyronitrile grown Rhodococcus sp. MTB5 free cells in exponential growth phase $\left(6.8 \times 10^{9} \mathrm{CFU} / \mathrm{ml}\right)$ were used as inoculum. The degradation process was carried out on a rotary shaker at $30{ }^{\circ} \mathrm{C}$ for $12,24,36,48,72,84$, and $96 \mathrm{~h}$ of incubation periods. All experiments were conducted in triplicate. Samples from the culture broth were withdrawn under sterile conditions at the above indicated time intervals to check the growth of the organism and for the analysis of residual butyronitrile. Butyronitrile $\%$ degradation, $\eta$, at different time periods of incubation was defined by the following expression:

Degradationratio, $\eta(\%)=\frac{S_{0}-S}{S_{0}} \times 100$

where $S_{0}$ represents the initial butyronitrile concentration (\%) prior to biodegradation; $S$ represents the residual butyronitrile concentration (\%) after degradation.

\section{Estimation of ammonia release}

Degradation of butyronitrile was even measured in terms of estimation of ammonia, as it is the indicator of nitrile cleavage and it is one of the end products in catabolism of nitriles. Production of ammonia from butyronitrile hydrolysis was quantitatively determined in the culture filtrate according to Vogel (1969).

\section{Preparation of cell-free extract}

The cells were harvested at mid-log growth phase by centrifugation at $8000 \mathrm{~g}$ for $10 \mathrm{~min}$ at $4{ }^{\circ} \mathrm{C}$ and washed twice with $100 \mathrm{mM}$ phosphate buffer (pH 7.0). The cellfree extract was prepared by following the procedure of Veeranagouda et al. (2006).

\section{Enzyme assays}

NHase activity was assayed in a reaction mixture comprised an appropriate amount of cell-free extract, $25 \mathrm{mM}$ butyronitrile and $100 \mathrm{mM}$ phosphate buffer $\mathrm{pH}$ 7.0. The reaction was administered at $37{ }^{\circ} \mathrm{C}$ for $15 \mathrm{~min}$ and arrested by adding $1 \mathrm{M} \mathrm{HCl}$. The mixture was then centrifuged at $8000 \mathrm{~g}$ for $10 \mathrm{~min}$, and the resulting supernatant was used for the analysis of butyramide by GC. One unit of NHase activity was defined as the amount of enzyme catalysing the formation of $1 \mu \mathrm{mol}$ of butyramide per min under assay conditions.

The amidase activity was assayed in a reaction mixture containing phosphate buffer $(100 \mathrm{mM}, \mathrm{pH} 7.0)$, $50 \mathrm{mM}$ butyramide, and appropriate amount of cell-free extract and incubated for $30 \mathrm{~min}$ at $37{ }^{\circ} \mathrm{C}$ in a water bath. The reaction was stopped by the addition of $1 \mathrm{M}$ $\mathrm{HCl}$ and centrifuged. The amount of ammonia released was measured according to Schär et al. (1986). One unit of amidase activity was defined as the amount of enzyme catalysing the formation of $1 \mu \mathrm{mol}$ of ammonia per min. 


\section{Metabolite feeding experiments}

The butyramide and butyric acid are the two metabolic intermediates of butyronitrile degradation (Mukram et al. 2015). For further confirmation of complete degradation of butyronitrile, we have checked the ability of the organism to utilize these intermediate metabolites as sole source of carbon and/or nitrogen. Feeding experiment was carried out by supplying these metabolites to the strain MTB5 as growth substrates in $250 \mathrm{ml}$ flasks containing $50 \mathrm{ml}$ MS media. The media used for the butyric acid feeding study were supplied with the $1 \mathrm{mg} \mathrm{ml}{ }^{-1}$ of $\mathrm{NH}_{4} \mathrm{NO}_{3}$ as the nitrogen source. Butyronitrile grown cells ( $5 \% \mathrm{v} / \mathrm{v}$ culture) were harvested by centrifugation at $8000 \mathrm{~g}$ for $10 \mathrm{~min}$ and washed with phosphate buffer used as inoculum. The flasks were incubated on shaker at $30{ }^{\circ} \mathrm{C}$, simultaneously incubated culture flasks without metabolites as well as uninoculated flasks containing metabolites served as controls. All these experiments were performed in triplicates. The growth of the bacteria, residual butyramide, and butyric acid concentration was determined.

\section{Growth of Rhodococcus sp. MTB5 on increasing butyronitrile concentrations}

To five $250 \mathrm{ml}$ flasks containing $50 \mathrm{ml}$ of MS medium, different concentrations of butyronitrile $(3.5-5.5 \%)$ were supplemented and the flasks were inoculated with exponential growth phase cells of strain MTB5. All the flasks were incubated in shaker at $30^{\circ} \mathrm{C}$, and the growth was determined at regular intervals of time.

\section{Analytical methods}

Bacterial growth was determined spectrophotometrically at $660 \mathrm{~nm}$ (analytikjena-SPECORD 50). Butyronitrile, butyramide and butyric acid concentrations were determined by gas chromatography (GC). The GC model used and the chromatographic conditions followed were as described previously (Mukram et al. 2015).

\section{Results}

\section{Butyronitrile degradation}

$2.0 \%$ of butyronitrile was completely degraded within $60 \mathrm{~h}$ of incubation, and at the same period, the strain attained its maximum growth $\left(\mathrm{A}_{660} \mathrm{~nm}, 1.345\right)$ (Fig. 2a). Maximum growth was observed at $72 \mathrm{~h}$ of incubation $\left(\mathrm{A}_{660} \mathrm{~nm}, 1.499\right)$ when Rhodococcus $\mathrm{sp}$. MTB5 was grown in MS medium with $2.5 \%$ butyronitrile as the sole carbon and nitrogen source. The strain showed $98 \%$ utilization of
$2.5 \%$ butyronitrile (Fig. 2b) within $72 \mathrm{~h}$. When the butyronitrile concentration was further increased to $3.0 \%$, maximum growth of the organism was seen at $96 \mathrm{~h}$ of incubation $\left(\mathrm{A}_{660} \mathrm{~nm}, 1.669\right)$ and showed $88 \%$ utilization of $3.0 \%$ butyronitrile (Fig. 2c). No further degradation of $3.0 \%$ butyronitrile was observed even after prolonged incubation. The free cells have successfully degraded butyritrile within $60 \mathrm{~h}$ of incubation when the concentration of butyronitrile was $2.0 \%(\mathrm{v} / \mathrm{v})$. When nitrile concentration was increased to 2.5 and $3.0 \%$, the rate of degradation was slightly decreased. Furthermore, when its concentration was increased beyond $3 \%$, the degradation efficiency was further decreased (data not shown). Furthermore, the higher concentration of butyronitrile adversely influenced the viability of the cells. In the control experiment, the concentration of butyronitrile remained the same in uninoculated culture flasks containing butyronitrile. This confirmed the utilization of butyronitrile as a consequence of hydrolysis of butyronitrile by Rhodococcus sp. MTB5. The concentration of ammonia was estimated at various time intervals with the maximum accumulation of 160,195 , and $205 \mathrm{mg} \mathrm{l}^{-1}$ for 2, 2.5, and $3 \%$ butyronitrile degradation, respectively (Fig. 3).

\section{Enzyme assays}

NHase and amidase are the two enzymes involved in the butyronitrile degradation in Rhodococcus sp. MTB5 were assayed. The NHase activity was found to be $0.194 \mu \mathrm{mol}$ of butyramide per min of incubation per $\mathrm{ml}$ of cell-free extract, whereas amidase activity was calculated to be $0.524 \mu \mathrm{mol}$ of ammonia per min of incubation per $\mathrm{ml}$ of cell-free extract.

\section{Feeding experiments}

Both the metabolites were found to be efficiently metabolized by the strain (Fig. 4). When the strain was grown in MS medium provided with butyramide as carbon and nitrogen source, the organism attained the maximum growth within $18 \mathrm{~h}$ of incubation. The maximum growth was indicated by optical density at $660 \mathrm{~nm}$ wavelength as 1.181 , and then, it entered stationary growth phase. It completely utilized butyramide in $21 \mathrm{~h}$ of incubation. The growth of the strain was also investigated in the presence of butyric acid. Strain reached stationary phase in $21 \mathrm{~h}$, and the maximal optical density at $660 \mathrm{~nm}$ wavelength was 1.465. Butyric acid was completely utilized by MTB5 in $18 \mathrm{~h}$ of incubation. These observations confirm the ability of Rhodococcus sp. strain MTB5 to utilize butyronitrile metabolites. Based on the results obtained, the butyronitrile degradation in Rhodococcus sp. MTB5 follows a bi-enzymatic NHase and amidase pathway (Fig. 5). 

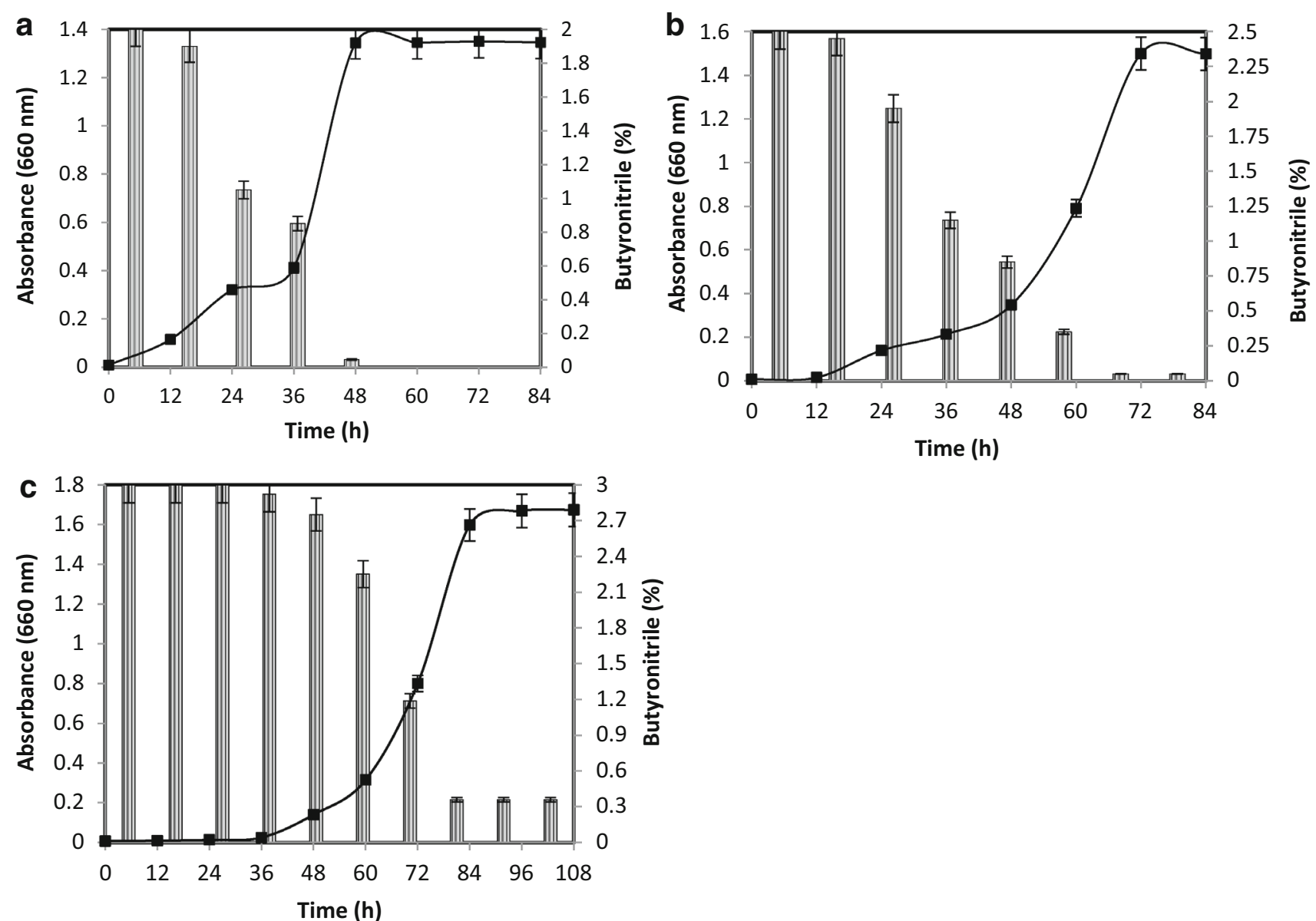

Fig. 2 Growth of Rhodococcus sp. MTB5 and degradation of $2 \%$ (a), $2.5 \%$ (b) and $3 \%$ (c) butyronitrile. Growth (filled squares); butyronitrile (dashed columns)

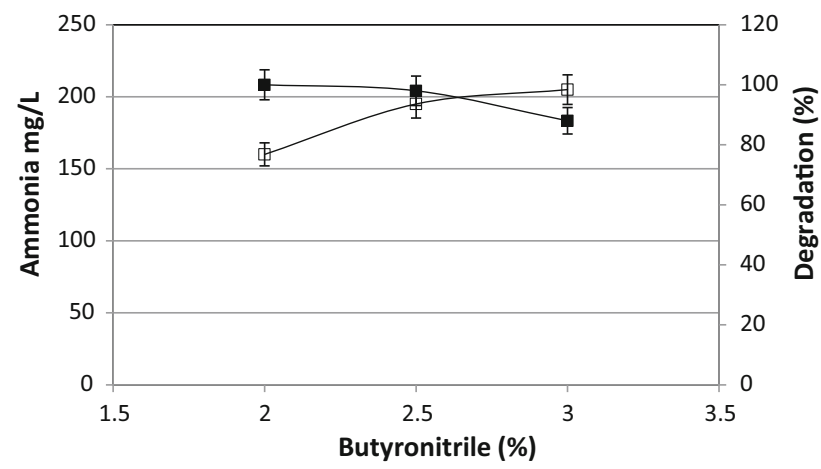

Fig. 3 Amount of ammonia (open squares) released and \% degradation (filled squares) of 2, 2.5, and $3 \%$ butyronitrile by Rhodococcus sp. MTB5

Growth of Rhodococcus sp. MTB5 was investigated at increasing concentrations of butyronitrile (Fig. 6). The highest growth was observed at $3.5 \%$ butyronitrile concentration, and above this concentration, the growth of the bacterium decreased gradually. However, concentrations above $4 \%$ induced a prolonged lag phase in bacterial growth. Conversely, beyond $5.5 \%$ of butyronitrile growth was completely suppressed.

\section{Discussion}

As per the available literature, the degradation of aliphatic nitriles follows through NHase and amidase pathway (Santoshkumar et al. 2011). Large numbers of reports are available on the degradation of aliphatic nitriles and most of them are on acetonitrile (Sorokin et al. 2007; Manolov et al. 2005; Feng and Lee 2009). However, only limited reports are available on the degradation of butyronitrile (Wenzhong et al. 1991; Nawaz et al. 1992), and among them, most reports are on the growth of the microorganisms on butyronitrile as carbon and/or nitrogen source (Nawaz et al. 1989; Linardi et al. 1996; Kao et al. 2006).

Nawaz et al. (1992) reported the NHase and amidase catalysed degradation of $36 \mathrm{mM}$ of butyronitrile by Klebsiella pneumonia in $96 \mathrm{~h}$ of incubation. Two strains of bacteria, Corynebacterium boffmanii and Arthrobacter 
Fig. 4 Growth of Rhodococcus sp. MTB5 on metabolites, butyramide, and butyric acid, butyramide (open squares) and butyric acid (filled squares); utilization of butyramide (open triangles) and butyric acid (filled triangles) and their utilization. Growth on

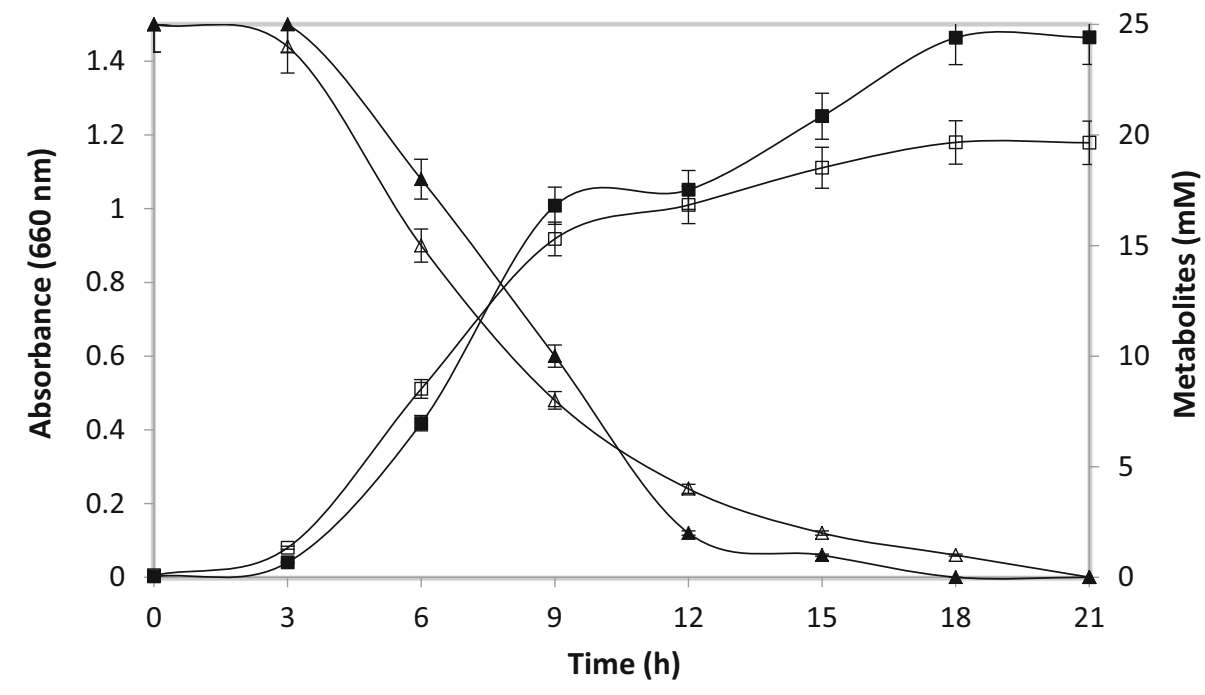

Fig. 5 Catabolic pathway of butyronitrile in Rhodococcus sp. strain MTB5

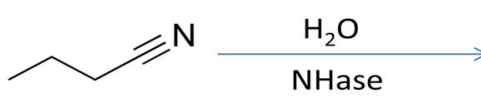

Butyronitrile

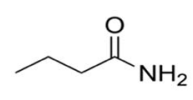

Butyramide

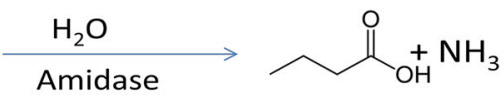

Butyric acid
Fig. 6 Growth of Rhodococcus sp. MTB5 on increasing concentrations of butyronitrile: $3.5 \%$ (filled squares), $4 \%$ (open squares), $4.5 \%$ (filled triangles), $5 \%$ (open triangles) and $5.5 \%$ (filled circles)

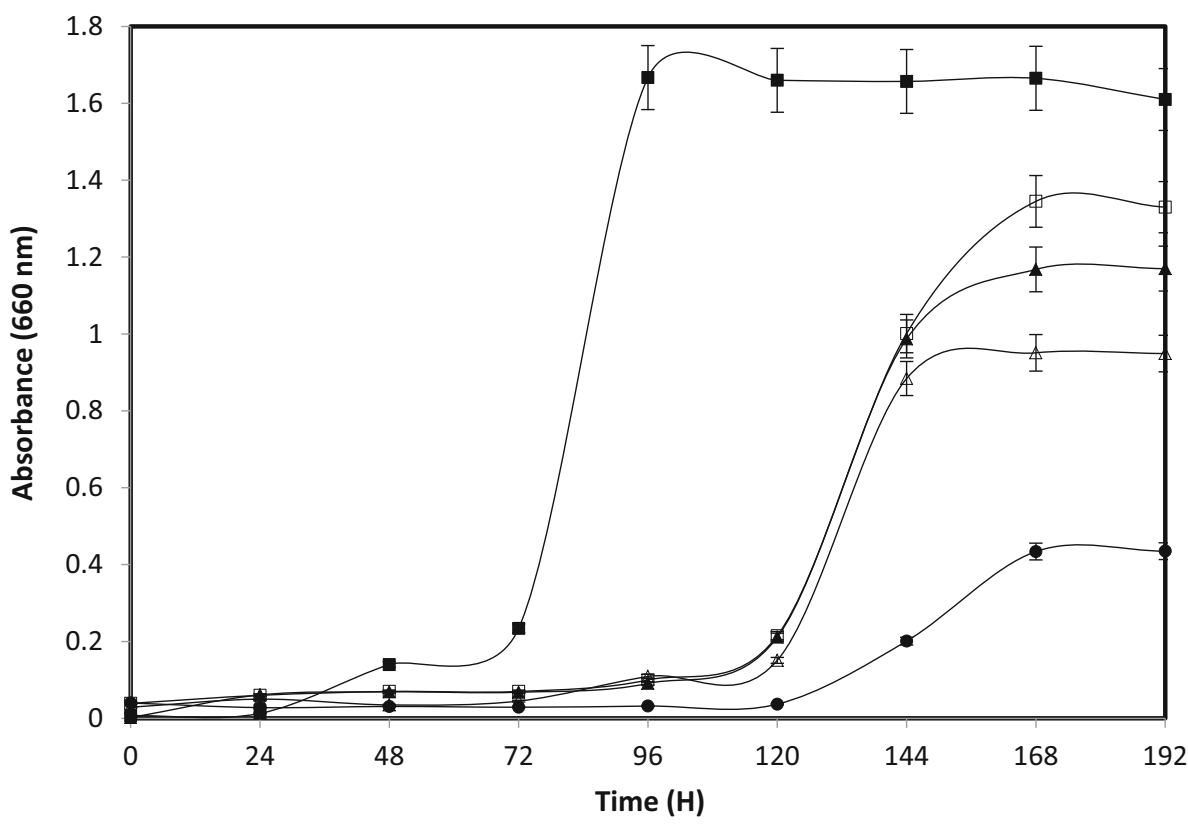

flavescens, were reported for the $100 \%$ removal of butyronitrile of concentration $10 \mathrm{~g} \mathrm{l}^{-1}$ in 12 and $36 \mathrm{~h}$ of incubation, respectively (Wenzhong et al. 1991). Pseudomonas putida was reported to grow on $0.2 \%$ butyronitrile as a sole source of carbon and nitrogen, and the utilization was shown in terms of accumulation of ammonia (Nawaz et al. 1989). Kao et al. (2006) reported the effects of butyronitrile concentration $(25,50$ and $100 \mathrm{mM})$ on the growth of Klebsiella oxytoca where in, $100 \mathrm{mM}$ butyronitrile induced an apparent lag phase in bacterial growth and its rate of degradation decreased and the time required was around $125 \mathrm{~h}$. Burkholderia cepacia strain C-3 capable of degrading butyronitrile was demonstrated in terms of growth on butyronitrile, as carbon and nitrogen source was reported by Adjei and ohta (1999). Kaur et al. (2014) isolated nitrile-hydrolysing bacterium Isoptericola variabilis RGT01 and showed its hydrolysing ability against $100 \mathrm{mM}$ butyronitrile. Acetonitrile and benzonitrile 
grown terrestrial and deep-sea actinomycete isolates were reported for having the butyronitrile hydrolyzing activities and the ability of butyronitrile as growth substrate for these isolates (Brandão and Bull 2003). The Candida famata isolated by Linardi et al. (1996) was able to grow on $0.7 \%$ butyronitrile, as nitrogen source and ammonia concentration was detected in the supernatant. On the other hand, in the present communication, we have reported the 100, 98, and $88 \%$ degradation of $2,2.5$, and $3 \%$ butyronitrile, respectively, by Rhodococcus sp. MTB5. The utilization was further confirmed by the accumulation of ammonia in the culture medium and by enzyme assay studies. To the best of our knowledge, this is the highest amount of degradation achieved for any of the nitriles by any microorganism reported so far.

Since last three decades, many studies on degradation of different types of nitriles have been carried out. All the studies reports that either nitriles will be directly converted to acids and ammonia or by the intermediate formation of amide. The amide and/or acid are detected in the spent medium during the course of nitrile degradation, and later, they will disappear (Fang et al. 2015; Kao et al. 2006; Brandão and Bull 2003; Li et al. 2007). However, no reports are available in the literature which confirms the complete degradation of given nitrile by both metabolite (amide and acid) feeding experiment. Fang et al. (2015) reported enzymatic degradation of aliphatic nitriles by Rhodococcus rhodochrous BX2. Furthermore, the authors showed the complete degradation in terms of utilization of carboxylic acid by this microorganism but not the amide. Similarly, the carboxylic acid degradation has been demonstrated in Cryptococcus sp. UFMG-Y28 (Rezende et al. 2000). In our previous studies, we reported butyramide and butyric acid as the metabolites of butyronitrile degradation (Mukram et al. 2015). In the present investigation, we have carried out metabolite feeding experiment by allowing the organism to grow on the metabolites and then estimating the residual metabolite concentration in the culture medium. The complete disappearance of amide and acid may imply that the given nitrile can be thoroughly decomposed to $\mathrm{CO}_{2}$ and $\mathrm{H}_{2} \mathrm{O}$. Furthermore, the utilization of intermediate products, i.e., the metabolites, is a positive attribute for the bioremediation of polluted environments, because the inhibition of microbial enzyme activities by intermediate products will be reduced. Furthermore, this action will avoid the secondary pollution from by-products that usually result in negative effects (Feng and Lee 2009). Degradation of such a high concentration of butyronitrile and conformation by metabolite feeding experiment is a notable property of Rhodococcus sp. MTB5 and serves to be potential candidate for the removal of high amounts of butyronitrile from the industrial effluent.
Acknowledgments Authors would like to thank the University Grants Commission (UGC), New Delhi, India for financial support in the form of Special Assistance Programme (SAP) sanctioned to the department [F3-15/2009(SAP-II)]. One of the authors, Mukram Ismailsab wishes to thank Gulbarga University for providing financial assistance through University research studentship to meritorious students (URSMS) [GUG/DEV-III/2014-15/131].

\section{Compliance with ethical standards}

Conflict of interest Author declares no conflict of interest.

Open Access This article is distributed under the terms of the Creative Commons Attribution 4.0 International License (http:// creativecommons.org/licenses/by/4.0/), which permits unrestricted use, distribution, and reproduction in any medium, provided you give appropriate credit to the original author(s) and the source, provide a link to the Creative Commons license, and indicate if changes were made.

\section{References}

Adjei MD, Ohta Y (1999) Isolation and characterization of cyanide utilizing Burkholderia cepacia strain. World J Microb Biotechnol 15:699-704

Banerjee A, Sharma R, Banerjee UC (2002) The nitrile-degrading enzymes: current status and future prospects. Appl Microbiol Biotechnol 60:33-44

Brandão PF, Bull AT (2003) Nitrile hydrolysing activities of deep-sea and terrestrial mycolate actinomycetes. Antonie Van Leeuwenhoek 84:89-98

Chen CY, Chen SC, Fingas M, Kao CM (2010) Biodegradation of propionitrile by Klebsiella oxytoca immobilized in alginate and cellulose triacetate gel. J Hazard Mater 177:856-863

Ebbs S (2004) Biological degradation of cyanide compounds. Curr Opin Biotechnol 15:231-236

Fang S, An X, Liu H, Cheng Y, Hou N, Feng L, Huang X, Li C (2015) Enzymatic degradation of aliphatic nitriles by Rhodococcus rhodochrous $\mathrm{BX} 2$, a versatile nitrile-degrading bacterium. Bioresour Technol 185:28-34

Feng YS, Lee CM (2009) The potential of the acetonitrile biodegradation by Mesorhizobium sp. F28. J Hazard Mater 164:646-650

Kao CM, Chen KF, Liu JK, Chou SM, Chen SC (2006) Enzymatic degradation of nitriles by Klebsiella oxytoca. Appl Microbiol Biotechnol 71:228-233

Kaur G, Soni P, Tewari R, Sharma R (2014) Isolation and characterization of a nitrile-hydrolysing bacterium Isoptericola variabilis RGT01. Indian J Microbiol 54:232-238

Kobayashi M, Shimizu S (1998) Metalloenzyme nitrile hydratase: structure, regulation and application to biotechnology. Nat Biotechnol 16:733-736

Kobayashi M, Shimizu S (2000) Nitrile hydrolases. Curr Opin Chem Biol 4:95-102

Legras JL, Chuzel G, Arnaud A, Galzy P (1990) Natural nitriles and their metabolism. World J Microb Biotechnol 6:83-108

Li T, Liu J, Bai R, Ohandja DG, Wong FS (2007) Biodegradation of organonitriles by adapted activated sludge consortium with acetonitrile-degrading microorganisms. Water Res 41:3465-3473

Linardi VR, Dias JC, Rosa CA (1996) Utilization of acetonitrile and other aliphatic nitriles by a Candida famata strain. FEMS Microbiol Lett 144:67-71 
Manolov T, Kristina H, Benoit G (2005) Continuous acetonitrile degradation in a packed-bed bioreactor. Appl Microbiol Biotechnol 66:567-574

Mukram I, Nayak AS, Kirankumar B, Monisha TR, Reddy PV, Karegoudar TB (2015) Isolation and identification of a nitrile hydrolyzing bacterium and simultaneous utilization of aromatic and aliphatic nitriles. Int Biodete Biodegr 100:165-171

Nawaz MS, Chapatwal KD, Walfram JH (1989) Degradation of acetonitrile by Pseudomonas putida. Appl Environ Microb 55:2267-2274

Nawaz MS, Davis JW, Wolfram JH, Chapatwala KD (1991) Degradation of organic cyanides by Pseudomonas aeruginosa. Appl Biochem Biotechnol 28(29):865-875

Nawaz MS, Heinze TM, Cerniglia CE (1992) Metabolism of benzonitrile and butyronitrile by Klebsiella pneumonia. Appl Environ Microb 58:27-31

Peter P, Gérard R, Ferdinand H, Heinz-Peter G (2002) "Nitriles" Ullmann's encyclopedia of industrial chemistry. Wiley-VCH Weinhei, Weinheim, Germany

Prasad S, Raj J, Bhalla TC (2009) Purification of a hyperactive nitrile hydratase from resting cells of Rhodococcus rhodochrous PA34. Indian J Microbiol 49:237-242

Ramakrishna C, Dave H, Ravindranathan M (1999) Microbial metabolism of nitriles and its biotechnological potential. J Sci Ind Res 58:925-947

Rezende RP, Dias JC, Ferraz V, Linardi VR (2000) Metabolism of benzonitrile by Cryptococcus sp. UFMG-Y28. J Basic Microb 40:389-392

Santoshkumar M, Veeranagouda Y, Lee K, Karegoudar TB (2011) Utilization of aliphatic nitrile by Paracoccus sp. SKG isolated from chemical waste samples. Int Biodeterior Biodegrad 65:153-159

Sauvage F, Chhor S, Marchioro A, Moser J, Graetzel M (2011) Butyronitrile-based electrolyte for dye-sensitized solar cells. J Am Chem Soc 133:13103-13109

Schär HP, Holzman W, Ramos TGM, Ghisalba O (1986) Purification and characterization of $N, N$-dimethylformamidease from Pseudomonas DMF 3/3. Eur J Biochem 158:469-475

Sharma M, Sharma N, Bhalla TC (2013) Purification studies on a thermo-active amidase of Geobacillus pallidus BTP-5x MTCC 9225 isolated from thermal springs of Tatapani (Himachal Pradesh). Appl Biochem Biotechnol 169:1-14

Sorokin DY, van Pelt S, Tourova TP, Takaichi S, Muyzer G (2007) Acetonitrile degradation under haloalkaline conditions by $\mathrm{Na}$ tronocella acetinitrilica gen. nov. sp. nov. Microbiol 153:1157-1164

Veeranagouda Y, Emmanuel Paul PV, Gorla P, Siddavattam D, Karegoudar TB (2006) Complete mineralization of dimethylformamide by Ochrobactrum sp. DGVK1 isolated from the soil samples collected from the coalmine leftovers. Appl Microbiol Biotechnol 71:369-375

Vogel AL (1969) Quantitative inorganic analysis including elementary instrumental analysis, 3rd edn. Low \& Bryodne Ltd, London 784

Wang Y, Zheng Y, Xue J, Shen Y (2007) Characterization of nitrile hydratation catalysed by Nocardia sp.108. World J Microb Biotechnol 23:355-362

Wenzhong L, Hongyi Z, Huifang Y (1991) Study on nitrile degrading microorganisms. J Environ Sci 3:91-97 